\title{
Integração como possibilidade de valorização do trabalho terceirizado nos Institutos Federais
}

\author{
Hylariane Rosa Ribeiro Artmann \\ Instituto Federal do Rio Grande do Sul (IFRS) - Campus Porto Alegre \\ (hylariane.artmann@osorio.ifrs.edu.br) \\ Michelle Camara Pizzato \\ Instituto Federal do Rio Grande do Sul (IFRS) - Campus Porto Alegre \\ (michelle.pizzato@poa.ifrs.edu.br)
}

\begin{abstract}
Resumo: O presente trabalho faz parte de uma pesquisa que busca estudar possibilidades de integração dos trabalhadores terceirizados nos Institutos Federais de Educação, e de que maneira essas Instituições colocam ou podem colocar em prática a premissa do trabalho como princípio educativo. A escolha do tema motivou-se pela reflexão da centralidade do trabalho na vida do ser humano, e na reflexão das condições desses trabalhadores dentro da nossa Instituição. Neste trabalho, especificamente, busca-se verificar se há alguma atividade dentro da Instituição que os terceirizados participam e se há ações destinadas à integração por parte dos Diretores de Administração. A pesquisa, de caráter qualitativo, utilizou como instrumento para a produção de dados um questionário, aplicado com os Diretores de Administração dos 17 Campi do Instituto Federal de Educação, Ciência e Tecnologia do Rio Grande do Sul (IFRS). Os resultados parciais apontam para um suposto conhecimento superficial ou desconhecimento, por parte dos terceirizados, sobre a missão e os objetivos da instituição, e para a valorização, por parte dos diretores, da realização de ações de integração dos terceirizados com seu local de trabalho, sem deixar de observar as normativas vigentes e sem deixar de cumprir as obrigações contratuais. Com essa pesquisa pretende-se contribuir na perspectiva de construir um ambiente profissional que valorize o trabalhador terceirizado, para que ele se sinta parte da Instituição, colocando em prática o princípio de que o que ocorre em uma instituição de ensino é educativo, seguindo uma lógica oposta ao neoliberalismo, valorizando o ser humano como sujeito cidadão através de uma educação integral.
\end{abstract}

Palavras-chave: Terceirização; Trabalho como princípio educativo; Integração.

\section{Integration as a possibility of valorization of outsourced work in Federal Institutes}

Abstract: The present work does part of a research that searches to study possibilities of integration of the outsourced workers in the Federal Institutes of Education, and of that way these institutions put or will be able to put in practice the premise of work as a educational principle. The choice of the subject had motivated for reflection of the centrality of work in the life of the human being, and in the reflection of the conditions of these workers within our institution. In this work, specifically, searches to check if there is any activity within the Institution that the outsourcers participate and if there are actions dedicate the integration by part the managing director. The research, of qualitative nature, used how instrument for the data production a questionnaire, applied with the managing director of seventeen (17) campus of the Federal Institute of Education, Science and Technology of Rio Grande do Sul (IFRS). The partial results aim for supposed superficial knowledge or lack of knowledge, by part of the outsourced, about the mission and objectives of the institution, and for the valorization by part the directors, accomplishment of actions of integration of the outsourcers with their workplace, without to allow of observe and comply the current regulations and meeting contractual obligations. With this research intends to contribute in the perspective of builds a professional environment that values the outsourced worker, so that he feels part of the institution, putting in practice the principle that what happens in an educational institution is educational, following a logic opposed to neoliberalism, valuing the human being as a citizen subject through an integral education.

Keywords: Outsourcing; Work as a educational principle; Integration. 


\section{INTRODUÇÃO}

Essa pesquisa tem como tema a integração dos trabalhadores terceirizados nas Instituições Públicas de Ensino, tendo como perspectiva o trabalho como princípio educativo, como uma forma de valorização do trabalhador no sentido oposto da precarização do trabalho na lógica neoliberal.

A motivação das pesquisadoras se deu ao verificarem que o setor de contratos do Campus da mestranda conta com orientações apenas referentes a parte documental, no que se refere às obrigações trabalhistas, sentindo falta de ações que promovam o acolhimento desses trabalhadores e integração ao ambiente de trabalho. Com essas inquietações chegamos ao problema de pesquisa: Quais as possibilidades de integração de trabalhadores terceirizados em uma instituição pública de ensino desde a perspectiva do trabalho como princípio educativo?

Sendo assim, essa pesquisa visa auxiliar na construção de um ambiente de trabalho acolhedor e integrador, que proporcione uma melhora nas condições de trabalho para os terceirizados, contribuindo na formação integral do ser humano que perpassa nossos corredores, visando uma sociedade mais justa e igualitária. Também conduzir os envolvidos, terceirizados, gestores e servidores, a um maior entendimento sobre a relação contratual existente entre Instituição/Empresa/Terceirizado, para abertura de um espaço de integração sem deixar de seguir as normativas vigentes.

Com a promulgação da Lei $\mathrm{n}^{\circ} 13.429$ de março de 2017, foi regulamentada a terceirização no país, tema que estava sendo debatido no Congresso através do Projeto de Lei $n^{\circ}$ 4.330/2004, o qual hoje encontra-se na Câmara dos Deputados sob a denominação de Projeto de Lei da Câmara n 30/2015. Para a promulgação da referida Lei, o texto sobre a regulamentação da terceirização foi incluído ao Projeto de Lei $\mathrm{n}^{\circ}$ 4.302/1998 que inicialmente tratava apenas do trabalho temporário. $\mathrm{O}$ DIEESE, Departamento Intersindical de Estatísticas e Estudos Socieconômicos, em nota técnica em abril de 2017 , já explicitou sua crítica quanto a forma como foi aprovada a Lei das Terceirizações:

Devido a extrema complexidade do tema e aos múltiplos impactos, a regulamentação da terceirização deveria ser tratada em lei específica, cujo o conteúdo tentasse abarcar os diversos elementos envolvidos nas relações entre contratantes e terceiras, entre as terceiras e os empregados e entre as contratantes e os terceirizados. (DIEESE, 2017, p.7). 
A Lei $n^{\circ} 13.467$ de julho de 2017 altera a Consolidação das Leis Trabalhistas e modifica o artigo $4^{\circ} \mathrm{A}$ da Lei $\mathrm{n}^{\circ} 6.019$ de janeiro de 1974, aprovando, sem deixar dúvidas, a terceirização para todos os tipos de atividades, o que antes estava restrito apenas às atividades meios, atividades acessórias da empresa; agora se estende também às atividades fins, podendo a empresa terceirizar até mesmo sua atividade principal. A terceirização da atividade-fim sempre foi muito criticada por autores que veem na terceirização a abertura para a precarização do trabalho, como já se manifestou o sociólogo Ricardo Antunes na audiência do Tribunal Superior do Trabalho em 2011.

Em um posicionamento diametralmente antagônico aos dos integrantes do quarto grupo e de defesa incondicional da proteção de direitos sociais que são entendidos como conquistas históricas dos trabalhadores, o sociólogo Ricardo Antunes argumentou que a terceirização é a porta de entrada para a flexibilização, a precarização e a informalidade. (BARBOSA e SILVA, 2015, p.89).

Viana (2017) também vê com negatividade a terceirização, segundo o autor essa modalidade de trabalho enfraquece os sindicatos e o caráter coletivo da classe, fragiliza o Direito do Trabalho na sua função de estabelecer normas protetivas, dificulta a fiscalização dos encargos trabalhistas e ainda traz aos trabalhadores consequência à sua dignidade, pois o terceirizado acaba sendo visto como um objeto.

[...] o empregador já não compra ou aluga simplesmente a força de trabalho, mas o homem por inteiro - ossos, cérebro, músculos - e em seguida o subloca a outra empresa, ganhando na diferença de preço. E assim o trabalhador se coisifica da maneira mais completa possível. (VIANA, 2017, p. 68).

A Administração Pública também tem utilizado a terceirização com a transferência de atividades para o setor privado desde 1967, com a Reforma Administrativa que propunha a diminuição da máquina estatal, e com a extinção de cargos em 1998.

O Instituto Federal de Educação, Ciência e Tecnologia do Rio Grande do Sul (IFRS), criado em 2008, através da Lei $\mathrm{n}^{\circ}$ 11.892, terceiriza atividades como: limpeza, vigilância, copeiragem, intérprete de libras, entre outras; através do processo de licitação contratamos empresas especializadas em prestação de serviços. Sendo a terceirização uma modalidade de trabalho que vem ganhando espaço tanto na esfera privada quanto na pública, e considerando que essas 
atividades sempre estarão presentes dentro da nossa Instituição, a pesquisa e a reflexão desse tema são de extrema relevância.

O Projeto Pedagógico Institucional (PPI), documento constante no Plano de Desenvolvimento Institucional (PDI 2019-2023) do IFRS, apresenta a dimensão político-pedagógica que guia a Instituição, e tem a educação como elemento fundamental para contribuir na transformação da sociedade, levando o ser humano a compreensão de ser inacabado que se constitui historicamente na relação com o outro, compreendendo as relações de poder existentes, e assumindo a posição de sujeito, de cidadão capaz de lutar por mudanças.

No contexto do mundo do trabalho, nossa Instituição visa o trabalhador como centro do processo, portanto a educação não deve estar voltada para atender as demandas do mercado, mas sim para uma educação omnilateral, que proporciona uma educação profissional voltada para a crítica e para a reflexão, não reproduzindo a clássica divisão entre conhecimento geral e conhecimento técnico, divisão que fortalece a dualidade estrutural.

\begin{abstract}
Assim, acredita-se na superação da divisão social do trabalho que separou ao longo da história o homem entre o pensar e o fazer, o dirigir e o planejar. Superando a compreensão do trabalho estranho e alienado, que se opõem à construção de uma sociedade humanizada, com olhar voltado ao trabalho no sentido ontológico. (IFRS 20192023, p.136).
\end{abstract}

Uma educação que possibilite a formação de cidadãos capazes de pensar e de agir com autonomia na busca da transformação da sociedade em que vivem. Mais ainda, Arruda (2012) escreve que para isso acontecer é necessária uma transformação da estrutura e das instituições, abrangendo para além da escola esse papel.

Trata-se, portanto, de abrir as portas do processo educativo para a sociedade e o mundo e de transformar em educadores todos os membros da sociedade, desde os dirigentes de governos, sindicatos e associações diversas, até os trabalhadores e os pais e mães de família. (ARRUDA, 2012, p. 101).

Tendo esses princípios como norteadores da nossa prática educativa, não temos também o dever de estendê-los aos trabalhadores terceirizados que por alguns anos dividem conosco o ambiente de trabalho? Para que estes possam encontrar no IFRS um local que contribua na construção da sua cidadania, do seu sujeito. Em um ambiente que assume a Gestão Democrática do ensino, podemos 
abrir espaços para que essas pessoas participem do contexto de educação integral que promovemos, conforme o próprio PDI (2019-2023) que nos traz uma citação de Ricardo Antunes:

Nesse sentido, vive-se numa democracia caracterizada pela organização política que reconhece cada sujeito como membro da comunidade/sociedade, a quem cabe discutir, refletir, pensar, opinar e transformar as questões coletivas. Isso remete à democracia escolar que se efetiva através da gestão democrática, entendida "como uma das formas de superação do caráter centralizador, hierárquico e autoritário que a escola vem assumindo ao longo dos anos" (ANTUNES, 2002, p.131, apud IFRS 2019-2023, p. 137).

Ao assumirmos o trabalho como princípio educativo, não podemos pensar no trabalho alienado, rotinizado, sem sentido, que serve apenas como moeda de troca para a sobrevivência, mercadoria para o capitalismo. Mas reafirmamos a posição de Saviani (2007) ao tratar o trabalho como algo da essência do homem, utilizando-se da natureza para suprir suas necessidades, e no trabalho se produz, social e historicamente. Saviani (2012) nos explica o significado de "trabalho como princípio educativo", primeiramente de forma teórica:

Portanto, quando consideramos o trabalho como princípio educativo, estamos querendo dizer que o trabalho, enquanto elemento fundante e determinante da vida humana em seu conjunto é, por consequência, fundante e determinante da educação. Ou seja: uma vez que o trabalho é "condição natural eterna da vida humana", em qualquer sociedade o trabalho se comporta como princípio educativo, isto é, determina a forma como é constituída e organizada a educação. (SAVIANI, 2012 p. 175).

Em seguida o autor explicita o trabalho como princípio educativo na sua concepção estratégica:

Nesse caso, dizer que o trabalho é princípio educativo significa tomálo como referência para se organizar a educação de maneira contrahegemônica procurando articulá-la com o movimento revolucionário de superação do capitalismo. (SAVIANI, 2012, p. 178).

Temos o trabalho como um direito fundamental criado no Estado Social de Direito, momento constitucional em que o Estado passa a ter interferência legal na vida das pessoas, criando políticas sociais. O Direito do Trabalho passa a agir na proteção ao trabalho visando proteger a parte mais fraca da relação entre trabalhadores e patrões, concedendo direitos ao trabalhador. 
Pode-se dizer então que o Estado Social construiu um conjunto de direitos (ditos como sociais), que foram capazes de ofertar ao ser humano melhoria substancial de condições de vida. $O$ trabalho permanente, subordinado, realizado por pessoa física, tornou-se não apenas forma de sobrevivência, mas meio de inclusão social eficaz e abrangente. (ROCHA e ANDRADE, 2014, p. 95).

Conforme Rocha e Andrade (2014), após o Estado de Direito temos o Estado Democrático, e no Brasil o marco da democracia é a Constituição de 1998, tendo o trabalho como direito social no artigo $6^{\circ}$, sendo considerado um direito fundamental, essencial na vida do ser humano, devendo ser resguardado. Sendo assim, o trabalho não pode ser visto apenas pelo viés econômico, mas tem um papel social.

A ideia de que trabalho não é mercadoria tem, portanto, um sentido jurídico fundamental. Uma vez estabelecida como princípio jurídico, permite proteger institucionalmente o trabalhador das leis de mercado. Contudo, mais do que importância jurídica, é atribuído ao trabalho um valor normativo, no sentido de que ele contribui para um desenvolvimento orientado à igualdade social e não apenas à acumulação. (MOSSI, 2019, p. 244).

Sendo o trabalho algo tão importante na vida do ser humano, um ambiente de trabalho saudável passa pela valorização. O que ocorre muitas vezes é o que Costa (2008) chama de "invisibilidade pública", ao estudar sobre psicologia social através da observação participante do dia a dia dos garis, o autor relata a invisibilidades dessas pessoas ao desenvolverem seu trabalho na Universidade de São Paulo.

A invisibilidade pública é resultado de um processo histórico de longa duração. Rebaixa a percepção de outrem, especialmente a percepção de alguém vinculado à forma baixa de trabalho assalariado, o trabalho desqualificado, alienado e alienante. (COSTA, 2008, n.p).

$\mathrm{Na}$ área da Psicodinâmica do Trabalho, o autor Dejours fala sobre o trabalho e sua relação de amor e ódio; Rodrigues, Álvaro e Rondina (2006) trazem a visão desse autor sobre esses sentimentos:

Percebe-se, assim, que o trabalho está conformado pelo afeto. Essa idéia de afeto implica "amor" ou "ódio" ao trabalho e gera outros binômios paralelos: "alegria" ou "tristeza", "entusiasmo" ou "desânimo", "anelo" ou "desprezo". Como a grande maioria das vezes, o trabalho acaba se associando mais à ideia de sofrimento, as pessoas acabam rompendo o conceito afeto/trabalho tornando 0 primeiro restrito ao lar, à família, expulsando o segundo de sua relação afetiva; e, assim, o trabalho fica desafetivado e, conseqüentemente, insuportável (RODRIGUES, ÁLVARO e RONDINA, 2006, s/p). 
Já França (2015) traz a questão da cooperação entre os trabalhadores baseada também no autor Dejours:

\begin{abstract}
Dejours (2008) defende que a cooperação, colaboração entre trabalhadores à organização do trabalho, assegura a vontade das pessoas de trabalharem juntas e superarem coletivamente as contradições que surgem da própria natureza ou da essência da organização prescrita do trabalho, atuando decisivamente tanto em relação a eficiência do trabalho quanto em relação à economia do sofrimento. (FRANÇA, 2015, p.45).
\end{abstract}

\title{
MATERIAIS E MÉTODOS
}

A pesquisa está classificada como o Estudo de Caso, tendo como foco um dos Campi do Instituto Federal de Educação, Ciência e Tecnologia do Rio Grande do Sul, contando como participantes os terceirizados e os servidores deste Campus. Para ampliar a compreensão do tema, foram convidados a participar os Diretores de Administração dos 17 Campi, através de um questionário, sendo esse artigo a discussão dos dados produzidos por suas respostas.

Essa pesquisa, de caráter qualitativo, está vinculada ao Programa de PósGraduação em Educação Profissional e Tecnológica (ProfEPT) do Instituto Federal de Educação, Ciências e Tecnologia do Rio Grande do Sul (IFRS) e demais instituições associadas. Trata-se de uma pesquisa aplicada que tem como delineamento o Estudo de Caso, sendo prevista a intervenção das pesquisadoras com o grupo de trabalhadores terceirizados de um dos Campi do IFRS.

A produção de dados se dará através de entrevistas semiestruturadas e a realização de Círculos de Cultura através da metodologia de Paulo Freire. Ainda será realizado um questionário com os servidores desse Campus para compreender a percepção destes em relação ao trabalho e ao trabalhador terceirizado. Também se propõe uma entrevista com o Procurador Federal que atua no IFRS para compreender as limitações legais da Administração frente aos terceirizados que trabalham na nossa Instituição.

Para ampliar a compreensão do tema, foram convidados a participar também os Diretores de Administração (DAPs) dos 17 Campi, através de um questionário (Quadro 1), sendo esse artigo a discussão dos dados produzidos por suas respostas. 
Buscou-se, com isso, verificar a compreensão dos DAPs quanto a terceirização e as possibilidades de integração desses trabalhadores com o ambiente de trabalho.

Quadro 1 - Questionário enviado aos Diretores de Administração.

\section{Questionário para os Diretores de Administração do IFRS.}

\section{Perfil do participante.}

1-Nome:

2-Campus de atuação:

3-Área de Formação:

4-Tempo na função de Diretor de Administração:

\section{Sobre a terceirização.}

5-A terceirização, como prestação de serviço especializado, atende as expectativas para as quais foram licitadas? Explique seu posicionamento.

6-As empresas cumprem as obrigações trabalhistas?

( ) Sim cumpre, nunca tivemos esse tipo de problema;

( ) Sim cumprem, contudo é necessário estar sempre cobrando da empresa;

( ) Não sei responder;

( ) Não cumprem. Já tivemos esse tipo de problema;

( ) Não cumprem. O Campus já enfrentou processos trabalhistas por esse motivo. Espaço para comentários:

\section{Sobre integração dos trabalhadores terceirizados}

7- Os terceirizados, que atuam no seu Campus, conhecem a Instituição, nossa missão e nossos objetivos enquanto projeto de educação?

( ) Sim, os terceirizados conhecem a Instituição e o nosso projeto educacional;

( ) Conhecem a Instituição de maneira superficial;

( ) Não sei responder;

( ) Não conhecem e não compreendem o que a Instituição representa no contexto educacional.

Espaço para comentários.

8-Quais destas atividades realizadas no seu Campus os terceirizados participam? Marque as opções que se enquadram à sua realidade.
( ) Projetos de Extensão;
( ) Atividades Culturais e/ou Palestras;
( ) Reuniões;
( ) Confraternizações;
( ) Outras;
( ) Nenhuma atividade.

9-Você considera importante a realização de ações que promovam a integração dos terceirizados com seu local de trabalho? Quais atividades poderiam ser desenvolvidas para promover a integração?

10-A integração de terceirizados, com a Instituição e com os servidores, pode prejudicar o desenvolvimento dos serviços prestados por esses trabalhadores? Por 
quê?

11-O Campus possui algum protocolo, ou ação para receber os terceirizados que iniciarão suas atividades na Instituição? Se sim, descreva.

\section{RESULTADOS}

Dos 17 Diretores convidados obtivemos o retorno de 11 participantes. Primeiramente foi realizado um breve perfil dos DAPs, onde podemos observar uma diversificada formação acadêmica entre: administração, direito, contabilidade, ciências sociais, educação, área da saúde e também ciências agrárias. Sobre o tempo em que estão atuando à frente da Direção de Administração e Planejamento encontramos servidores que a poucos meses assumiram a função, entre 04 a 11 meses, a maioria está atuando a mais de 3 anos, e poucos que já ultrapassaram o período de uma gestão (Quadro 2).

Quadro 2 - Demonstrativo do tempo atuando na função de Diretor de Administração:

\begin{tabular}{|l|l|l|l|}
\hline Tempo na Gestão & Menos de 1 ano & De 3 a 5 anos & Mais de 5 anos \\
\hline $\begin{array}{l}\text { Quantidade de } \\
\text { diretores }\end{array}$ & 3 & 6 & 2 \\
\hline
\end{tabular}

Sobre as licitações realizadas nos Campi, os diretores foram questionados se os serviços contratados atendem às expectativas para as quais foram licitadas, essa pergunta foi formatada em estilo texto livre, para obter uma resposta mais completa. Alguns DAPs se mostraram satisfeitos com o serviço e com as empresas terceirizadas: "Acredito que, em que pese os problemas enfrentados, atendem os objetivos e ainda são a melhor opção." (DAP 15); "Sim, atendem as expectativas e necessidades conforme objetos propostos nos instrumentos editalícios." (DAP 8).

Mas tivemos respostas parciais, nas quais manifestaram problemas na licitação atraindo empresas sem estrutura para a prestação do serviço, e ainda que a baixa remuneração dificulta a contratação de bons profissionais, atraindo pessoas com pouca motivação para o trabalho. "Serviço precarizado com baixa remuneração para seus trabalhadores o que reduz a qualidade e dificulta a seleção de bons profissionais." (DAP 4). E ainda:

As expectativas são atendidas parcialmente, muitas vezes, a baixa remuneração dos trabalhadores (ainda que de acordo com a CCT), traz para o trabalho profissionais pouco qualificados e com baixa 
motivação. O resultado é um trabalho desenvolvido de forma precária, demandando mais esforço e desgaste com a fiscalização do mesmo, e por consequência, de todos aqueles servidores envolvidos na gestão do contrato. (DAP 24).

Relataram também que o contingenciamento de recursos financeiros acaba por subestimar a força de trabalho necessária. Outros apontaram que atendem as expectativas, mas que também se faz necessária uma fiscalização eficaz da administração.

Ainda sobre as empresas contratadas, foi questionado se as mesmas cumprem com suas obrigações trabalhistas, mais da metade dos diretores responderam que sim, mas que é necessário que a Administração cobre a empresa pelo cumprimento (Quadro 3). Um diretor afirmou já ter enfrentado penalizações, e outro relata: "Atrasos em salários, falta de recursos para verbas rescisórias, falta de preposto, um lixo de serviço." (DAP 2). Outro diretor esclarece:

Já tivemos todo tipo de situação com empresas terceirizados. O que pude observar é que quanto maior o tamanho da empresa, mais organizada ela é. Contratos menores de um ou dois terceirizados tendem a apresentar maiores problemas, pois atrai empresas menores e iniciantes no mercado. (DAP10).

Quadro 3 - Respostas para a questão $n^{\circ} 6$ : As empresas cumprem as obrigações trabalhistas?

\begin{tabular}{|l|r|}
\hline Opções de Resposta & Quantitativo \\
\hline Sim cumpre, nunca tivemos esse tipo de problema & 1 \\
\hline $\begin{array}{l}\text { Sim cumprem, contudo, é necessário estar sempre cobrando da } \\
\text { empresa }\end{array}$ & 8 \\
\hline $\begin{array}{l}\text { Não sei responder } \\
\text { Não cumprem. Já tivemos esse tipo de problema }\end{array}$ & 1 \\
\hline $\begin{array}{l}\text { Não cumprem. O Campus já enfrentou processos trabalhistas por } \\
\text { esse motivo }\end{array}$ & 1 \\
\hline
\end{tabular}

Os DAPs também foram questionados sobre sua opinião frente aos trabalhadores terceirizados dos seus Campi, se estes conheciam a Instituição e o projeto de educação, neste ponto a maioria respondeu que estes trabalhadores conhecem a Instituição de maneira superficial ou que não conhecem(Quadro 4). "Em relação aos terceirizados, pela baixa escolaridade, há a dificuldade do entendimento 
do projeto e da Missão institucional." (DAP 5). "Não possuímos uma política de integração dos terceirizados com a comunidade acadêmica." (DAP 10).

Quadro 4 - Respostas para a questão n ${ }^{\circ}$ : Os terceirizados, que atuam no seu Campus, conhecem a Instituição, nossa missão e nossos objetivos enquanto projeto de educação?

Opções de Resposta

Quantitativo

Sim, os terceirizados conhecem a Instituição e o nosso projeto educacional

Conhecem a Instituição de maneira superficial

Não sei responder

Não conhecem e não compreendem o que a Instituição representa no contexto educacional

Também foi perguntando se os terceirizados participam de atividades desenvolvidas no Campus, as confraternizações são as atividades em que há mais participação, em alguns Campus há a participação em atividades culturais e poucos manifestaram participação em projetos de extensão e reuniões (Quadro 5). Ainda recebemos respostas de que os terceirizados não participam de nenhuma atividade.

Quadro 5 - Respostas para a questão n 8: Quais destas atividades realizadas no seu Campus os terceirizados participam? Marque as opções que se enquadram à sua realidade (escolha de múltiplas

Opções de Respostas respostas).

Projetos de Extensão

Atividades Culturais e/ou Palestras

Quantitativo

Reuniões

Confraternizações

Outras

Nenhuma atividade

2

Sobre a integração de terceirizados com o seu local de trabalho, perguntamos sobre a importância dessa atitude, deixando a resposta livre para manifestação dos participantes. Todos manifestaram a importância da integração, entre as respostas, encontramos que ações nessa direção trariam maior confiança, reforçariam o sentimento de pertencimento e seriam uma forma de valorização, ocasionando um melhor desempenho das funções. Ainda podemos identificar algumas ações descritas pelos gestores na intenção de demonstrar a valorização desses trabalhadores em seus Campi: "[...] eles precisam ser valorizados e se sentir parte da instituição, desta forma desempenham melhor suas funções. Aqui convidamos 
frequentemente para reuniões, palestras e confraternizações." (DAP 15). "Acho importante, desde que observe-se a legislação vigente." (DAP 5). Outro diretor salientou: "[...] nós da administração valorizamos os funcionários terceirizados, repassamos a importância que eles possuem e fizemos alguns almoços no ano as nossas custas, o que gera um pouco mais de confiança entre a instituição e eles [...]." (DAP 2).

Para complementar o entendimento, perguntamos se na opinião dos diretores a integração poderia interferir no trabalho dos terceirizados, no geral os diretores acreditam que não; "Creio que não. A integração dos terceirizados somente beneficia no desenvolvimento dos serviços prestados" (DAP 1). "Não é só questão de organizar" (DAP 8). Alguns acreditam que pode prejudicar em alguns aspectos: "Dependendo do perfil dos servidores e dos terceirizados, sim. O excesso de pessoalidade pode dificultar as tratativas entre gestão-terceirizados." (DAP 10). "Só em casos raros nos quais os funcionários tomam a amizade como pretexto para sobreporem-se a legislação." (DAP 25). Segue manifestação de um diretor:

Acredito que a integração pode tanto prejudicar quanto ajudar no desenvolvimento dos trabalhos, pois estamos falando de pessoas, e elas tem suas particularidades, mas na relação de trabalho com terceirizados, acredito que tenhamos que deixar claro a relação de trabalho, respeitosamente impor os limites necessários para que possamos ter relações saudáveis. (DAP 3).

Por fim, perguntamos se há alguma ação de integração nos Campi, onde foi possível identificar que não, o que há são simples apresentações dos fiscais aos terceirizados e reuniões iniciais com os representantes da empresa, ações que fazem parte do Manual de Gestão e Fiscalização de Contratos do IFRS. Assim escreveu um dos diretores: "Não possui nada formalizado. Apenas as reuniões de início da prestação de serviços e reuniões periódicas com os representantes." (DAP 5). E também: "Ainda não temos, geralmente são realizadas reuniões iniciais com as equipes/encarregados onde são tratados os pontos mais relevantes do trabalho/contrato a ser desenvolvido." (DAP 24).

\section{DISCUSSÃO}

Sobre a contratação de serviços terceirizados, podemos observar que elas atendem em parte as expectativas para as quais foram licitadas, conforme as respostas dos Diretores, a dificuldade está em encontrar boas empresas, empresas 
sérias do ramo, e com estrutura suficiente para atender as demandas da contratação. "Entendo que sim, o objeto licitado na terceirização sempre nos atendeu de maneira satisfatório quando foi prestado por empresas sérias do ramo." (DAP 10). Empresas sem estrutura refletem em problemas nos serviços, a respeito disso temos a seguinte manifestação:

Depende da empresa, mas geralmente temos problemas, pois a licitação prevê o menor preço e assim com a concorrência sobram só empresas de fundo de quintal que não possuem margem para prestar um bom serviço. (DAP 2).

Os autores Salvino e Ferreira (2009) ao explicarem sobre a diferença entre a terceirização lícita e a ilícita (intermediação de mão de obra) esclarecem que para a licitude da terceirização, a empresa contratada deve ser especializada nos serviços prestados ao contratante, sendo assim: "Parte-se da premissa de que a empresa detém capacidade e organização para a consecução do serviço contratado, de forma a restringir-se, exclusivamente a sua finalidade." (SALVINO e FERREIRA 2009, p. 131).

No tocante a valorização do trabalho e a integração dos terceirizados, encontramos muitas posições positivas, de forma a manter uma relação profissional, mas que ao mesmo tempo seja sensível ao lado humano, cumprindo as obrigações contratuais; conforme alguns comentários de diretores: "É preciso manter uma relação profissional que compreende o lado do ser humano, mas procura manter a realização dos serviços da forma como previsto na contratação." (DAP 4).

A integração de terceirizados com a instituição e com os servidores, promove uma melhoria no desenvolvimento dos serviços, porque traz - colaborador para a Instituição, ele faz parte dela, tem responsabilidade para com ela e sua comunidade, deve ajudar a cuidar e preservar seu ambiente de trabalho. (DAP 24).

A fala do DAP 24 sobre a responsabilidade do trabalhador com seu ambiente de trabalho, ajudando a cuidar e preservar, vem de encontro ao que os autores Rodrigues, Álvaro e Rondina (2006) escrevem sobre o sentimento de bem-estar relacionado ao ambiente:

O bem-estar está relacionado à ideia de ambiente gratificante e, assim, quando o mesmo é realizado em tal ambiência, leva os trabalhadores a gostarem do produto realizado. Já, a ideia de sofrimento está relacionada à subjugação do trabalho e, quando isso ocorre, se imprime raiva ao produto. (RODRIGUES, ÁLVARO e RONDINA, 2006, s/p). 
Como escrevem os autores Salvino e Ferreira (2009) quando tratam da terceirização na Administração Pública:

Relevante o fato de a terceirização ser pensada não apenas sob o viés econômico, mas também considerando a dignidade do trabalhador terceirizado, ao qual se quer é possibilitada a vinculação ao ambiente de trabalho, onde passa a maior parte de sua vida. (SALVINO e FERREIRA, 2009, p. 137).

Para aprofundar a temática, além de pensar a terceirização na Administração Pública, precisamos pensar a terceirização em um ambiente educacional, dentro de uma Instituição que preza pela educação integral do cidadão, e reconhece o ser humano como um ser de relações que se constitui na convivência com os outros. Seguindo esse viés encontramos alguns posicionamentos na direção de uma integração entre terceirizados, Instituição e servidores:

Acreditamos ser importante a realização de ações que integrem os terceirizados, justamente por estes fazerem parte da nossa comunidade. Projetos que aproximem os funcionários terceirizados dos servidores, ações que promovam a participação dos terceirizados e reforce a conscientização sobre nosso modelo de educação e nosso público-alvo, são exemplos de atividades que, além de promover a integração reforçam o espírito de equipe e pertencimento dos terceirizados junto a instituição. (DAP 1).

É muito importante a realização de ações que integrem os terceirizados. Eles são profissionais fundamentais ao desenvolvimento da nossa missão enquanto instituição. Por isso, 0 sentimento de pertencimento é fundamental nesse caso. Quanto às atividades de integração, penso que a simples participação em reuniões gerais de "abertura de ano letivo" ou até mesmo em confraternizações de encerramento de ano, já é um bom começo. É possível também, que sejam promovidas capacitações periódicas (integração/reciclagens), a fim de abordar estas questões. (DAP 24).

Nas respostas dos diretores é possível identificar que mesmo não sendo parte da comunidade acadêmica que é composta por: discentes, docentes e técnicos, os terceirizados, de alguma forma são vistos como parte da Instituição ao afirmarem que "são profissionais fundamentais", "parte da nossa comunidade", "ele faz parte dela", "se sentir parte da Instituição", são alguns falas que aparecerem nos posicionamento dos DAPs ao serem questionados sobre a possibilidade de integração.

O reconhecimento do trabalho é importante para tornar o ambiente e o labor mais prazeroso, como escreve Lykawka (2013) ao citar o autor Dejours que trata da psicodinâmica do trabalho: 
Uma vez reconhecida a qualidade do meu trabalho, meus esforços, angústias, dúvidas, decepções, e desânimos também adquirirão sentido. Se o reconhecimento e a valorização não acontecerem, esvazia-se o sentido de ser trabalhador dando lugar, assim à insatisfação. (LYKAWKA, 2013, p. 10).

Por fim, verificamos que não há nos Campi uma ação específica destinada a integração dos terceirizados com a Instituição, o que há são reuniões com representantes das empresas, o que está previsto no nosso Manual de Gestão e Fiscalização de Contratos, com o objetivo de definir os procedimentos para o desenvolvimento do trabalho e esclarecer dúvidas. Outra ação apontada pelos DAPs, é a apresentação dos fiscais do contrato ao terceirizado, o que acaba sendo necessário já que o fiscal precisa conhecer as pessoas que prestarão os serviços no Campus.

\section{CONSIDERAÇÕES FINAIS}

O tema da terceirização, sem dúvida tem relevância dentro da nossa Instituição, visto que essa modalidade de trabalho continuará a ser contratada para a prestação de determinados serviços, considerando que essas funções não estão mais previstas no nosso quadro de cargos. Temos o dever de zelar pelo cumprimento dos direitos dos terceirizados que trabalham nos Campi de forma a não permitir ilegalidades na prestação dos serviços. E ainda, como Instituição de Ensino nossos valores e princípios precisam ser estendidos para esses trabalhadores que dividem conosco o ambiente de trabalho.

Os Diretores de Administração demonstraram interesse em promover a integração dos terceirizados com a Instituição e com os servidores, acreditando que é possível uma organização entre os envolvidos para que não haja prejuízo dos serviços prestados, tomando os devidos cuidados para que a pessoalidade não atrapalhe o cumprimento das obrigações contratuais. Essas dúvidas serão melhor esclarecidas com a entrevista com o Procurador Federal que atua no IFRS.

A pesquisa ainda analisará a opinião dos servidores sobre o assunto, e através de entrevistas semiestruturadas procurará investigar o senso de pertencimento dos terceirizados de um dos Campi da Instituição; como é a relação com a empresa e com seu local de trabalho, assim como, se na percepção destes, há valorização do seu trabalho. 


\section{REFERÊNCIAS}

ARRUDA, Marcos. A articulação trabalho-educação visando uma democracia integral. In: Trabalho e Conhecimento: dilemas na educação do trabalhador. GOMEZ, Carlos Minayo et al. 6 ed. São Paulo: Cortez, 2012.

BARBOSA, A.M. e SILVA, R.H. A audiência pública do TST sobre a terceirização como espaço de luta político-cognitiva. Política \& Sociedade. v.14, n.30, p. 72-101, mai./ago. 2015. Disponível em:

<https://periodicos.ufsc.br/index.php/politica/article/view/2175-7984.2015v14n30p72> Acesso em: 03 jan. 2019.

COSTA, Fernando Braga. Moisés e Nilce: retratos biográficos de dois garis. Um estudo de psicologia social a partir de observação participante e entrevistas. 2008. Tese (Doutorado em Psicologia), Universidade de São Paulo, São Paulo, 2008. Disponível em: <https://www.teses.usp.br/teses/disponiveis/47/47134/tde-09012009154159/publico/costafernando_do.pdf>. Acesso em: 14 mar. 2019.

DEPARTAMENTO INTERSINDICAL DE ESTATÍSTICAS E ESTUDOS SOCIECONÔMICOS. Impactos da Lei n 13.429/2017 (antigo PL 4.302/1998) para os trabalhadores. Nota Técnica $n^{0} 175$, abril/2017. Disponível em:

$<$ https://www.dieese.org.br/sitio/buscaDirigida?itemBusca=\&comboBuscaDirigida=TE MA\%7Chttp\%3A\%2F\%2Fwww.dieese.org.br\%2F2012\%2F12\%2Fdieese\%23T35691 2459:>. Acesso em 01 ago 2019.

FRANÇA, Lúcio, C.B. Relações Socioprofissionais de Trabalhadores Terceirizados: um estudo de caso numa Universidade Pública Federal. 2017. Dissertação de Mestrado (Pós-Graduação em Gestão de Projetos Institucionais), Universidade Federal do Rio Grande do Norte, Natal, 2017. Disponível em:

<https://repositorio.ufrn.br/jspui/handle/123456789/24330>. Acesso em 11 nov 2018.

GOMES, Carlos M. et al. Trabalho e Conhecimento: dilemas na educação do trabalhador. 6 ed. São Paulo: Cortez, 2012.

INSTITUTO FEDERAL DE EDUCAÇÃO, CIÊNCIA E TECNOLOGIA DO RIO GRANDE DO SUL (IFRS). Plano de Desenvolvimento Institucional (2019-2023). Disponível em: <https://ifrs.edu.br/pdi-2019-2023/> Acesso: 08 mar. 2019.

LYKAWKA, Liliane. O Trabalhado Terceirizado: Reconhecimento, Valorização e Satisfação. 2013. Monografia (Especialização de Psicologia), Universidade Federal de Rio Grande do Sul, Instituto de Psicologia, Porto Alegre, Rio Grande do Sul, 2013. Disponível em: <https://lume.ufrgs.br/handle/10183/76594>. Acesso em: 26 set 2019.

MOSSI, T. W. Lutas Trabalhistas como Lutas Minoritárias: a questão da dignidade do trabalhador terceirizado. Sociologias, Porto Alegre, ano 21, n. 50, p. 236-259, janabr 2019. Disponível em: <https://seer.ufrgs.br/sociologias/article/view/84846>. Acesso em: 31 jul de 2019. 
ROCHA, C. J.; ANDRADE, F. C. M. O Trabalho e o Direito do Trabalho Analisados sob as Perspectivas do Constitucionalismo e da Democracia. 2014. Disponível em: <https://www.e-publicacoes.uerj.br/index.php/quaestioiuris/article/view/10794> Acesso em: 08 jan. 2019.

RODRIGUES, P. F.; ÁLVARO, A. L. TRONDINA, R. Sofrimento no Trabalho na Visão de Dejours. Revista Científica Eletrônica de Psicologia. Ano IV, n. 7, nov. 2006. Disponível em:

$<$ http://faef.revista.inf.br/imagens_arquivos/arquivos_destaque/lh21p1ieajxlwck_2013 -5-10-15-30-2.pdf>. Acesso em: 05 mar. 2019.

SALVINO, M. R.; FERREIRA, S. R. Terceirização de serviços na administração pública e a responsabilidade trabalhista. Revista Novatio luris, Porto Alegre, ano 2, n 3, 119-146, jul. 2009. Disponível em:

<http://www.esade.edu.br/esade/user/file/Esade06.pdf>. Acesso em: 09 fev.2019.

SAVIANI, D. Trabalho e educação: fundamentos ontológicos e históricos. Revista Brasileira de Educação. v.12, n.34, 9. 152-180, jan./abr. 2007. Disponível em: <http://www.scielo.br/pdf/rbedu/v12n34/a12v1234.pdf> Acesso em: 06 dez. 2018.

SAVIANI, D.; DUARTE, N. Pedagogia histórico-crítica e luta de classes na educação escolar. São Paulo: Autores Associados, 2012.

VIANA, Márcio Túlio. Para entender a terceirização. 3 ed. São Paulo: LTr, 2017. 